\title{
Alkali Çözelti ile Karbondioksit Tutma Verimi Üzerine Alkil Aminlerin Etkisinin Araştırılması
}

\author{
Elifcan YOZCU, Neslihan TAŞDEMİR, Mehmet Hakan MORCALI* \\ Kahramanmaraş Sütçü İmam Üniversitesi, Mühendislik ve Mimarlkk Fakültesi, Çevre Mühendisliği Bölümü, \\ 46100, Avşar Kampüsü, Kahramanmaraş
}

\begin{abstract}
Öz
Sanayileşmenin ve tüketimin hız kesmeden devam etmesi sonucu açığa çıkan her türlü atık (sera gazları, firın atıkları/proses atıkları) çevrede çeşitli kirliliklere sebep olmaktadır. Yakın gelecekte atmosferdeki sera gazı miktarının ivmeli artışıla çok ciddi iklim değişikliklerinin yaşanabileceği beklenmektedir. Bu sebeple atmosferdeki en önemli sera gazlarından birisi olan karbondioksit gazının tutulması ve depolanmasına gün geçtikçe ihtiyaç artmaktadır. Bu çalışmada; sentetik olarak hazırlanmış alkali çözeltilerin karbondioksit tutma kapasitesine etki eden parametreler incelenmiştir. Sentetik çözeltiler hazırlanırken ülkemizdeki firın atıklarının (cüruflar) kimyasal bileşiminden esinlenilmiştir. En iyi deney şartlarının belirlenmesi için farklı konsantrasyonlara sahip çözeltiler hazırlanmış ve alkil amin türevlerinin karbondioksit tutma verimi üzerine olan etkileri karşılaştırılarak deneysel çalışmalar sonucu elde edilen çökeltiler çeşitli spektroskopik yöntemler ile karakterize edilmiş ve sonuçlar yorumlanmıştır.
\end{abstract}

Anahtar kelimeler: Endüstriyel katı atıklar, Sera gazı, Karbondioksit, Karbonatlaştırma.

\section{Investigation of Capturing Efficiency of Alkyl Amines on Carbon Dioxide in Alkaline Media}

\begin{abstract}
Continuing unabated industrialization and consumption continues to cause various pollutants in the environment as a result of this situation any kind of waste (greenhouse gases, oven residues/slags) is being formed. It is expected that very serious climate changes may occur with the acceleration of the amount of greenhouse gas in the atmosphere in the near future. For this reason, the demand of capturing and storing one of the most important greenhouse gas which is known as carbon dioxide in atmosphere is increasing day by day. In this study; the carbon dioxide capturing performance of alkaline solution which was prepared synthetically was investigated by assessing the effects of various parameters. While the synthetic solutions were prepared, the chemical composition of the oven residues (slags) was inspired. To determine the best experimental conditions, various synthetic solutions were prepared and the effects of alkyl amine derivatives were compared on capturing carbon dioxide. The precipited powders, which obtained experimental studies, were characterized by various spectroscopic methods.
\end{abstract}

Keywords: Industrial solid wastes, Greenhouse gas, Carbon dioxide, Carbonation.

\section{Giriş}

Son zamanlarda "küresel ısınma" ve/veya "iklim değişikliğì" konuları dünya çapında üzerinde durulan en popüler konular arasındadır. Küresel ısınmanın nedeni dünyamızda sera etkisi yaratan ve sera gazları diye adlandırılan karbon dioksit $\left(\mathrm{CO}_{2}\right)$, su buharı $\left(\mathrm{H}_{2} \mathrm{O}\right)$, azot oksitler $\left(\mathrm{NO}_{\mathrm{X}}\right)$, metan $\left(\mathrm{CH}_{4}\right)$, kükürt hekzaflorit $\left(\mathrm{SF}_{6}\right)$, hidroflorokarbon ( $\left.\mathrm{HFC}\right)$, perflorokarbon $(\mathrm{PFC})$ ve kloroflorakarbon $(\mathrm{CFC})$ gazlarıdır. Su buharı dışındaki sera gazlarında $\mathrm{CO}_{2}$ 'nin payı \%50'nin üzerindedir [1]. Günümüzde insan kaynaklı $\mathrm{CO}_{2(\mathrm{~g})}$ emisyonlarını engelleyebilsek dahi, atmosferdeki $\mathrm{CO}_{2(\mathrm{~g})}$ seviyesinin düşmesi ve küresel

\footnotetext{
*Sorumlu yazar: hmorcali@ksu.edu.tr

Geliş Tarihi: 25.04.2018, Kabul Tarihi: 06.07.2018
} 
ısınmanın önüne geçilmesi için doğanın kendisini yenilemesine güvenmekten başka çaremiz bulunmamaktadır. Fakat bu çaresizlik durumuna yeni çözümler bulabilmek için birçok uluslararası organizasyon ve ülkeler sera gazı emisyonlarının düşürülmesi için, yenilenebilir enerji kaynaklarının enerji üretiminde payının arttırılmasından sera gazı yakalama ve depolama kullanma teknolojilerinin geliştirilmesine verilen desteğin arttırılmasına kadar birçok eylem planında mutabık olunmuş ve uygulamalarına başlanmıştır [2-4].

Literatürde sera gazı yakalama işlemi ilk olarak mineral karbonatlaştırma yöntemi olarak adlandırılmıştır. Bu yöntemde silikatlı kayaçların sera gazı yakalamada kullanılması ve elde edilen ürünlerin depolanması veya çeşitli endüstrilerde hammadde olarak kullanılması amaçlanmıştır $[4,7]$. Doğal minerallerin kullanıldığı bu işlemler karbon yakalama ve depolama (carbon capture and storageCCS; KYD) ve karbon yakalama ve kullanma (Carbon Capture and Utilization-CCU; KYK) prosesleri olarak tanımlanmaktadır [3-6]. Bu yöntem doğadaki karbonatlı minerallerin uzun sürede ve uygun termodinamik koşullarda (basınç ve sıcaklık) oluşumlarından esinlenmiştir. İlk olarak 1990 yıllarda Seifritz tarafından çalışılmıştır ve doğadaki karbonat oluşumu süreçlerinin laboratuvar ortamında hızlandırılmış olarak tekrarlanması esnasına dayanmaktadır [5]. Daha sonra bu alanda sera gazlarının tutulmasi/depolanması gibi işlemlerde kullanılmak üzere birçok araştırmalar yapılmış ve yapılmaktadır. Sera gazı tutucuları genel olarak dört guruba ayrılmaktadır.

İnorganik esaslı kimyasal sorbentler [5],

Zeolit esaslı doğal sorbentler [6],

Organik sorbentler (Amin kökenli veya iyonik esaslı sıvı tutucular) [7],

Anyon değiştirici sorbentler [6-8],

Sera gazları için önemli bir teknolojik yöntem olan KYD yöntemi temel olarak, sera gazılarının (özellikle $\mathrm{CO}_{2}$ için) çeşitli tutucular ile tutulması ve gaz veya bileşik formunda depolanması prensibine dayanmaktadır. Bu bağlamda inorganik esaslı kimyasal sorbentler yapısal olarak bünyelerinde bulunan kalsiyum $(\mathrm{Ca})$, magnezyum $(\mathrm{Mg})$ sodyum $(\mathrm{Na})$, potasyum $(\mathrm{K})$ ve lityum $(\mathrm{Li})$ elementlerinin bazik bileşikleri (oksitli veya hidroksitli) karbondioksit $\left(\mathrm{CO}_{2(\mathrm{~g})}\right)$ su buharını $\left(\mathrm{H}_{2} \mathrm{O}_{(\mathrm{g})}\right)$ tutmada/depolamada $\left(\mathrm{CaMg}\left(\mathrm{CO}_{3}\right)_{2}, \mathrm{Ca}(\mathrm{OH})_{2}, \mathrm{Na}_{2} \mathrm{CO}_{3}, \mathrm{~K}_{2} \mathrm{CO}_{3}, \mathrm{Li}_{2} \mathrm{CO}_{3}\right.$ gibi) aktif rol almaktadır. İnorganik esaslı kimyasal sorbentler ile $\mathrm{CO}_{2(\mathrm{~g})}$ tutma veya depolama işlemi sırasında gerçekleşen kimyasal reaksiyonlar termodinamik açıdan mümkün olmasına rağmen kinetik açıdan engellerle doludur (süre, sicaklık ve basınç en önemli kriterler arasında) [2,9]. Reaksiyonun kinetik açıdan gerçekleşebilmesi için reaksiyon sırasında sıcaklık ve basıncın arttırılması kabul edilebilir bir sürede gerçekleşmesini sağlamaktadır.

Bazik çözeltiler veya bileşikler ile $\mathrm{CO}_{2}$ gazı tutma işlemine ait genel reaksiyonu denklem 1'de özetlenmektedir. Goeppert vd. tarafından 2012 yılında gerçekleştirilen çalışmada; $\mathrm{NaOH}$ çözeltisinin $25^{\circ} \mathrm{C}^{\prime}$ de $500 \mathrm{ppm} \mathrm{CO} 2$ içeren havayla karbonizasyonun çok yavaş ve 4 saatlik bir reaksiyon sonrasında sadece \%9'nu (45 ppm $\mathrm{CO}_{2}$ tutulmuş) tutabildiği tespit edilmiştir [7].

$\mathrm{CO}_{2}+2 \mathrm{OH}^{-}=\mathrm{CO}_{2}^{-2}+\mathrm{H}_{2} \mathrm{O}$

Bir başka çalışmada ise, $\mathrm{Ca}(\mathrm{OH})_{3}$ ve $\mathrm{CaO}$ 'nun karbonatlaşmasında sırasında ortamdaki suyun varlığının reaksiyonu hızlandırdı ve katalize ettiği tespit edilmiştir. İnorganik tutucular arasında en ekonomik olan $\mathrm{Ca}$ ile tutma işlemi için sıcaklık veya basıncın gerekli olduğu birçok çalışmada belirtilmiştir. Zeolit esaslı doğal bileşikler (ticari adı: $13 \mathrm{X}$ veya $\left.\mathrm{Na}_{86}\left[\left(\mathrm{AlO}_{3}\right)_{86}\left(\mathrm{SiO}_{3}\right)_{106}\right] .264 \mathrm{H}_{2} \mathrm{O}\right)$ kullanılarak önemli sera gazlarından olan $\mathrm{CO}_{2(\mathrm{~g})}$ ve su buharı $\left(\mathrm{H}_{2} \mathrm{O}_{(\mathrm{g})}\right)$ yukarda belirtilen reaksiyonda (reaksiyon 1) olduğu gibi benzer şekilde basınç altında tutulabilmektedir [10]. Fakat tekrardan kullanımı için (rejenerasyon işlemi) 1S1 gerektirmesi $\left(150-350^{\circ} \mathrm{C}\right)$ adsorpsiyon sonrası için çok enerji harcamaktadir.

Amin (RR'R' N; Ar- $\mathrm{NH}_{2}$ ) esaslı organik sorbentler ve iyonik esaslı siv1 tutucular (aminle modifiye edilmiş alkil bileşikler) $\mathrm{CO}_{2(\mathrm{~g})}$ gazı ile oda sıcaklığında kolaylıkla reaksiyona girerek amounyum karbonat teşkil etmektedir (Denklem 2) [10-15]. 

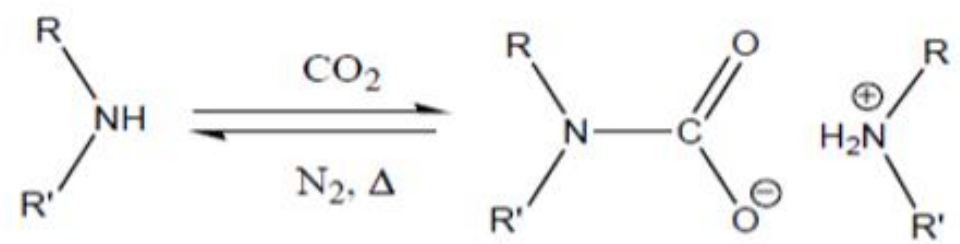

Amin ve karbon dioksit arasındaki reaksiyonlar genel olarak; zwitteriyon mekanizması, baz katalizli hidrasyon mekanizması ve üç moleküllü tepkime mekanizması olarak üç grupta sıralanabilir. Aminlerin bünyelerinde $\mathrm{CO}_{2(\mathrm{~g})}$ tutabilmesi (reaksiyonları) ortamda bulunan amin türüne bağlı olmakla birlikte ortamın nemliliğine de bağlidır. İlk önce hidroksil grubu $\left(\mathrm{OH}^{-}\right)$ile aktifleştirilen $\mathrm{CO}_{2}$ reaksiyon vermesi ile bikarbonat $\left(\mathrm{HCO}_{3}{ }^{-}\right)$oluşturur ve daha sonra tutma işlemi gerçekleşir. Tüm amin türevleri arasında aromatik aminler baziklik ve nükleofilik özelliklerinin az olmasından dolayı diğer aminlere göre daha zor reaksiyona girerler [14-18].

Bu makale kapsamında gerçekleştirilen çalışmalarda, karbondioksit tutucu olarak kullanılması düşünülen endüstriyel atıklar içerisinde var olabilecek katyonların etkilerini belirlemek için saf (pure) sistemler kullanılarak deneyler gerçekleştirilmiştir. Böylece karbondioksit $\left(\mathrm{CO}_{2}\right)$ tutma parametresine etki edecek kimyasal bileşiklerin etkileri net olarak ortaya konulmuştur. Elde edilen sonuçlar doğrultusunda, çevreyi iki farklı yoldan kirleten bu iki kirleticiden aynı anda kurtulmak ulaşılmak istenmektedir.

\section{Materyal ve Metot}

Deneylere başlamadan önce yapılan literatür taramasında karbondioksit tutmada en çok tercih edilen ve endüstriyel atıklarında bünyesinde bolca bulunan inorganik tuzları içeren farklı konsantrasyondaki çözeltileri hazırlanmıştır (Tablo 1). Yürütülen ön denemeler sonucu elde edilen bilgiler doğrultusunda çözeltinin $\mathrm{CO}_{2}$ gazı tutma kinetiğinin çok yavaş olması sebebiyle reaktörlere amin türevli katalizörler eklenmiştir. Piyasadan kolaylıkla temin edilebilecek ve literatürde sıklıkla kullanılan amin türevleri (primer, sekonder ve tersiyer) tercih edilmiştir.

Kullanılan amin türevlerinin $\mathrm{CO}_{2}$ tutma verimi üzerine etkileri araştırılmış ve kendi aralarında karşılaştırılmıştır. Karbondioksit ve amin arasında gerçekleşen reaksiyon üç mekanizma ile açıklanır. Bunlar iki yüklü iyon (zwitteriyon) mekanizması, baz katalizli hidrasyon mekanizması ve termoleküler reaksiyon mekanizmasıdır. Genel olarak gerçekleşen reaksiyon mekanizmasında birinci basamakta, karbondioksit ve amin reaksiyona girerek iki yüklü iyon (zwitteriyon) adı verilen ara ürünü oluşturur. İkinci basamakta ise, bu ara ürün ortamda bulunan bir baz ya da bazlar tarafindan deprotonasyona uğrayarak karbomat iyonu ve protonlanmış bazı oluşturur. Bu reaksiyon tipi primer $\left(\mathrm{RNH}_{2}\right)$ ve sekonder $\left(\mathrm{R}_{2} \mathrm{NH}\right)$ aminlerin karbondioksit ile reaksiyon kinetiğini açıklamaktadır [9]. Deneysel çalışmalar boyunca primer, sekonder ve tersiyer amin türleri kullanılmıştır. Deneylerde ilk olarak tersiyer amin türevi olan trietilamin $\left(\mathrm{N}\left(\mathrm{C}_{2} \mathrm{H}_{5}\right)_{3}\right)$ kullanılmış ve en iyi deneysel sonuçların elde edildiği şartlarda farklı amin türevlerinden olan sekonder amin; dibütilamin $\left(\left(\mathrm{C}_{4} \mathrm{H}_{9}\right)_{2} \mathrm{NH}\right)$ ve primer amin; etilendiamin $\left(\mathrm{C}_{2} \mathrm{H}_{4}\left(\mathrm{NH}_{2}\right)_{2}\right)$ kullanılarak sonuçlar yorumlanmıştır. Kullanılmas1 planlanan sodyum klorür $(\mathrm{NaCl})$, potasyum klorür $(\mathrm{KCl})$, amonyum klorür $\left(\mathrm{NH}_{4} \mathrm{Cl}\right)$ ve kalsiyum klorür $\left(\mathrm{CaCl}_{2}\right)$ konsantrasyonlarına ait veriler Tablo 1'de verilmiştir. Çözeltilerin bazikliği ise; \%25'lik amonyak çözeltisinden $1 \mathrm{~mL}$ kullanılarak sağlanmıştır. 
Tablo 1. Kullanılan kimyasallar ait farklı konsantrasyonlar.

\begin{tabular}{|c|c|c|c|c|c|c|c|}
\hline \multirow{2}{*}{ Kimyasallar } & \multicolumn{7}{|c|}{ Konsantrasyonlar, ppm (mg/L) } \\
\hline & 1000 & 1500 & 2000 & 3000 & 5000 & 7500 & 10000 \\
\hline $\begin{array}{l}\text { Sodyum Klorür } \\
(\mathrm{NaCl})\end{array}$ & $\mathrm{X}$ & $\mathrm{X}$ & $\mathrm{X}$ & $\mathrm{X}$ & $\mathrm{X}$ & - & - \\
\hline $\begin{array}{c}\text { Kalsiyum } \\
\text { Klorür }\left(\mathrm{CaCl}_{2}\right)\end{array}$ & $\mathrm{X}$ & $\mathrm{X}$ & $\mathrm{X}$ & $\mathrm{X}$ & $\mathrm{X}$ & $\mathrm{X}$ & $\mathrm{X}$ \\
\hline $\begin{array}{c}\text { Potasyum } \\
\text { Klorür }(\mathrm{KCl})\end{array}$ & $\mathrm{X}$ & - & - & - & - & - & - \\
\hline $\begin{array}{c}\text { Amonyum } \\
\text { Klorür }\left(\mathrm{NH}_{4} \mathrm{Cl}\right)\end{array}$ & $\mathrm{X}$ & - & - & - & - & - & - \\
\hline
\end{tabular}

Deneysel çalışmalar, 250 mL'lik reaktörlerde $200 \mathrm{~mL}$ çözelti kullanılarak gerkçekleştirilmiştir (Her bir reaktiften $50 \mathrm{~mL}$ kullanılmıştır). Tüm reaktörlere $1 \mathrm{~mL} \% 25^{\prime}$ lik $\mathrm{NH}_{4} \mathrm{OH}$ çözeltisinden ilave edilmiştir. Deneyler 1sıtıcı-karıştırıcılarda manyetik balık ile karıştırılarak karbondioksit $\left(\mathrm{CO}_{2}\right)$ tutabilme etkisi incelenmiştir. Deneylerde kullanılan gazlar (Azot; $\mathrm{N}_{2}$ ve Karbondioksit $\mathrm{CO}_{2}$ ) \% 99 saflıktadir.

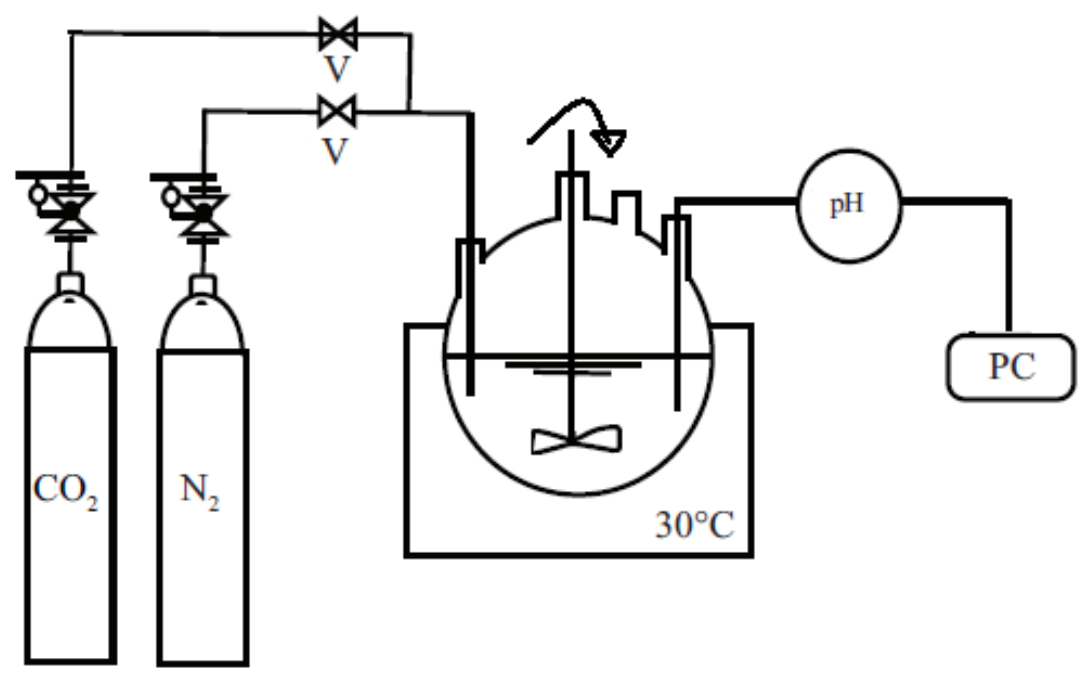

Şekil 1. Karbondioksit tutma reaktörünün şematik görüntüsü.

Deneyler sırasında oluşabilecek pozitif ve/veya negatif sapma en az indirmek için iki adet reaktör kullanılmış ve sonuçların ortalamaları hesaplanmıştır. Çalışmalar da ultra saf su cihazı kullanılmıştır $(0,055 \mu \mathrm{s} / \mathrm{cm})$. İki tekrarlı olarak gerçekleştirilen deneyler için karbondioksit $(\% 20)$ ve azot $(\% 80)$ gazlarının karışımı kullanılmıştır. Her deney için kullanılan numuneler Şekil 1'deki deney düzeneğine yerleştirilmiştir. Deneylere başlamadan önce örneklerin başlangıç $\mathrm{pH}$ 'ları ölçülüp kaydedilmiştir. Deney süresi boyunca belirli periyotlarda çözeltinin $\mathrm{pH}$ değerleri takip edilmiştir. Deney sonunda oluşan çökeltiler katı/sıvı ayrımı yöntemi ile filtre edilmiş ve kurutulmuştur. Tamamen kurutulmuş numuneler hassas terazide tartılarak elde edilen tartım sonuçları kaydedilmiştir. Daha sonra numuneler karakterize edilmek üzere hava geçirmez kilitli torbalara konulmuştur (Şekil 2). 


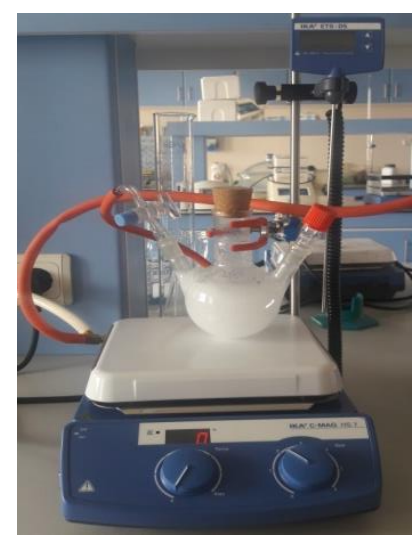

(A)

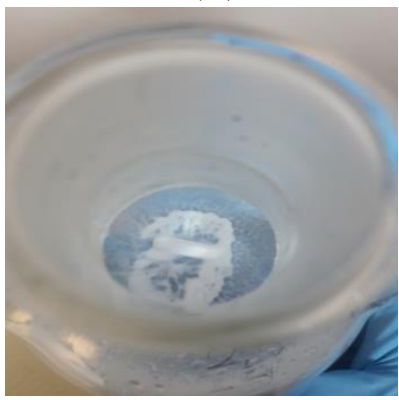

(D)

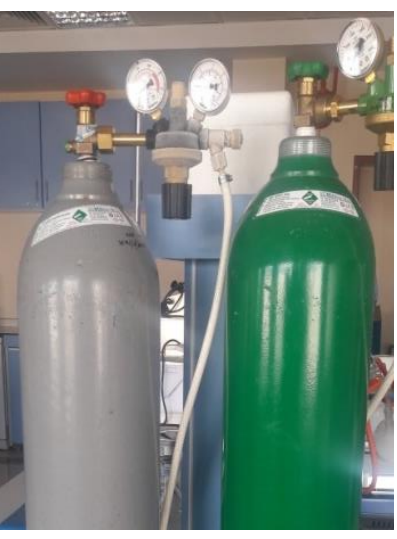

(B)

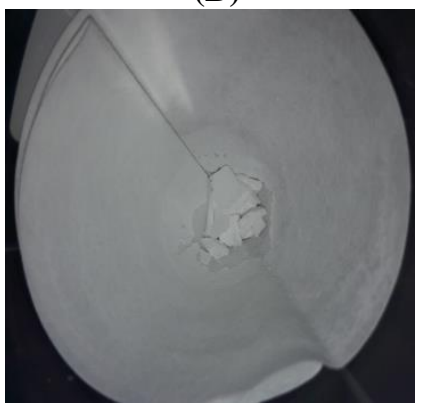

(E)

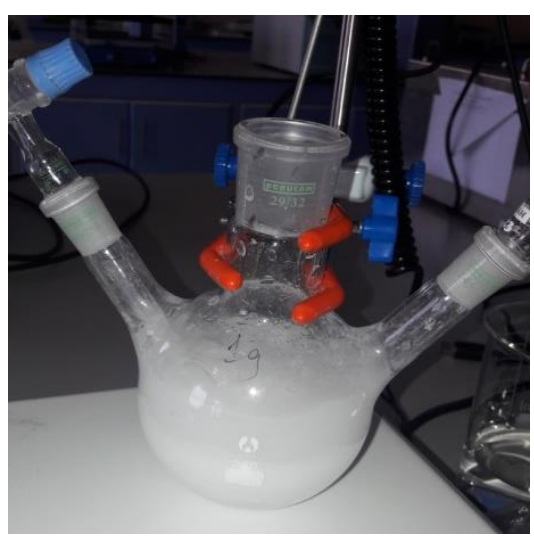

(C)

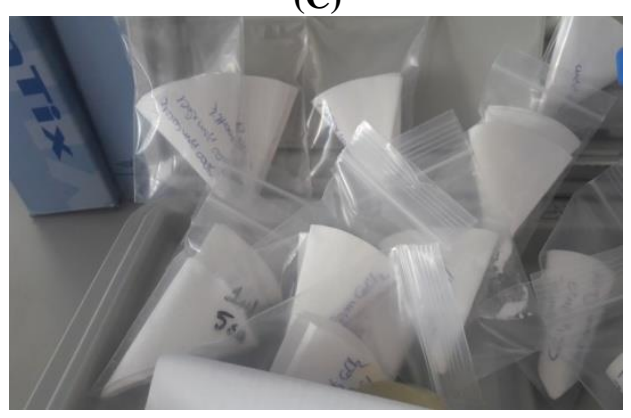

(F)

Şekil 2. Gerçekleştirilen deneylere ait resimler.

Her bir farklı parametrenin incelendiği deney sonrası elde edilen deney kalıntıları kurutularak tartılmıştır. En iyi tartım verimlerinin elde edildiği deneylere ait çökeltiler analiz edilerek sonuçlar yorumlanmıştır.

\section{Bulgular ve Tartışma}

\subsection{Kalsiyum konsantrasyonun $\mathrm{CO}_{2}$ tutma verimi üzerine etkisi}

Kalsiyum konsantrasyonun etkisinin belirlendiği bu çalışmada çözelti içerisinde bulunan kalsiyum iyonlarının miktarının $\mathrm{CO}_{2}$ tutma verimi üzerine etkileri incelenmiştir. Deneyler sırasında çözelti içerisindeki katyon miktarı $\left(1250 \mathrm{ppm} \mathrm{NH}_{4}^{+}, 250 \mathrm{ppm} \mathrm{K}{ }^{+}, 250 \mathrm{ppm} \mathrm{Na}{ }^{+}\right)$ve diğer parametreler $\left(25^{\circ} \mathrm{C}\right.$, 5 saat, $500 \mathrm{rpm}$ ve $1 \mathrm{~mL}$ trietilenamin) sabit tutulmuştur. $\mathrm{Ca}^{2+}$ konsantrasyonun değişimi ile elde edilen çökelti ağırlığının verildiği grafikten görüleceği (Şekil 3) üzere çözelti içerisindeki $\mathrm{Ca}^{2+}$ konsantrasyonun artışı ile birlikte çökelti miktarınında arttığı gözlenmektedir. Aslında bu artış beklenen bir durumdur.

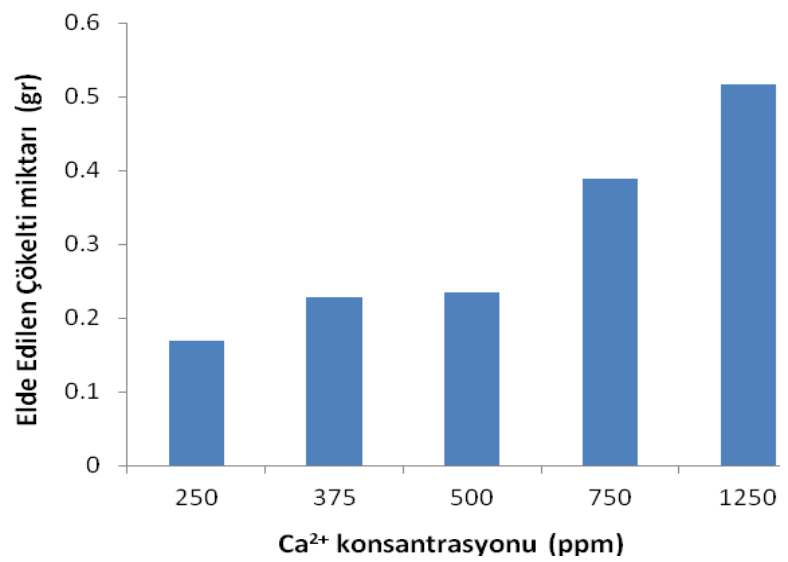

Şekil 3. Kalsiyum konsantrasyonun çökelti miktarına etkisi. 
Kalsiyum iyonları ortamda bulunan $\mathrm{CO}_{2}$ molekülü ile reaksiyon vererek $\mathrm{CaCO}_{3}$ bileşiğinin teşekkülünü sağlamaktadır. Oluşması beklenen $\mathrm{CaCO}_{3}$ bileşiğinin mineral kaynaklı sular içerisinde çözünmesi ve daha sonra çökelmesi 1sı işlemi ile yürümektedir[10].

$\mathrm{CO}_{2(\mathrm{~g})}+2 \mathrm{OH}_{(\mathrm{aq})}^{-} \rightarrow \mathrm{CO}_{3}{ }^{2-}{ }_{(\mathrm{aq})}+\mathrm{H}_{2} \mathrm{O}_{(\mathrm{s})}$ (gerçekleşebileceği reaksiyon $\left.\mathrm{pH}>10,3\right)$

$\mathrm{CO}_{2(\mathrm{~g})}+2 \mathrm{OH}_{(\mathrm{aq})}^{-} \rightarrow \mathrm{HCO}_{3}^{-}{ }_{(\mathrm{aq})}($ gerçekleşebileceği reaksiyon $6,3<\mathrm{pH}<10,3)$

Karbonat oluşum reaksiyonu; $\mathrm{Ca}^{2+}{ }_{(\mathrm{aq})}+\mathrm{CO}_{3}{ }^{2-}{ }_{(\mathrm{qq})} \rightarrow \mathrm{CaCO}_{3(\mathrm{k})}$ (gerçekleşebileceği reaksiyon $\mathrm{pH}>10,3$ )

$\mathrm{Ca}^{2+}{ }_{(\mathrm{aq})}+\mathrm{HCO}_{3}{ }_{(\text {aq) }}^{-} \rightarrow \mathrm{CaCO}_{3(\mathrm{k})}+\mathrm{H}^{+}{ }_{(\mathrm{aq})}($ gerçekleşebileceği reaksiyon $6,3<\mathrm{pH}<10,3$ )

İlk yapılan denemelerde ortamda bulunan $\mathrm{Ca}^{2+}$ iyonlarının reaksiyonun kinetiğinin çok yavaş olduğu bu reaksiyonun kinetik açıdan hızlandırılması ortama eklenen trietilamin ile sağlanmıştır [11]. Tablo 2'de reaksiyon sırasında ortama verilen $\mathrm{CO}_{2}$ gazının su içerisinde çözünerek ortamının $\mathrm{pH}$ değerini bazik bölgeden asidik bölgeye taşıdığı tespit edilmiştir.

Tablo 2. Kalsiyum $\left(\mathrm{Ca}^{2+}\right)$ konsantrasyonlarının $\mathrm{pH}$ üzerine etkisi.

\begin{tabular}{|c|c|c|c|c|c|c|c|c|c|c|c|c|}
\hline $\begin{array}{c}\mathrm{pH} \\
\text { Değişimi }\end{array}$ & Süre (dakika) & 0 & 30 & 60 & 90 & 120 & 150 & 180 & 210 & 240 & 270 & 300 \\
\hline \multirow{2}{*}{$\overline{0}$} & $250 \mathrm{ppm} \mathrm{Ca}^{2+}$ & 11,98 & 10,67 & 7,03 & 6,96 & 6,78 & 6,78 & 6,78 & 6,77 & 6,77 & 6,76 & 6,73 \\
\cline { 2 - 12 } & $375 \mathrm{ppm} \mathrm{Ca}^{2+}$ & 11,15 & 8,64 & 6,97 & 6,68 & 6,65 & 6,65 & 6,64 & 6,61 & 6,60 & 6,59 & 6,58 \\
\cline { 2 - 11 } & $500 \mathrm{ppm} \mathrm{Ca}^{2+}$ & 11,26 & 9,45 & 7,12 & 6,84 & 6,71 & 6,69 & 6,68 & 6,62 & 6,62 & 6,61 & 6,60 \\
\cline { 2 - 11 } & $750 \mathrm{ppm} \mathrm{Ca}^{2+}$ & 10,89 & 6,63 & 6,61 & 6,58 & 6,57 & 6,56 & 6,56 & 6,54 & 6,53 & 6,53 & 6,53 \\
\cline { 2 - 9 } & $1250 \mathrm{ppm} \mathrm{Ca}^{2+}$ & 11,34 & 6,52 & 6,49 & 6,47 & 6,44 & 6,44 & 6,43 & 6,41 & 6,40 & 6,40 & 6,40 \\
\hline \multirow{2}{*}{}
\end{tabular}

Reaksiyon sırasında pH değerinin kısa bir sürede hızla değiştiği gözlemlenmektedir. Bu değişim ortamdaki hidroksit $\left(\mathrm{OH}^{-}\right)$bileşiğinin karbondioksit tarafından tüketilerek nötralize edilmesinden kaynaklanmaktadır. En iyi çökelti veriminin elde edildiği $\mathrm{Ca}^{2+}$ iyon veriminin elde edildiği 1250 ppm'lik $\mathrm{Ca}^{+2}$ bir sonraki deneysel çalışmalarda kullanılmıştır.

\subsection{Sodyum konsantrasyonun $\mathrm{CO}_{2}$ tutma verimi üzerine etkisi}

Bir önceki çalışmada elde edilen veriler doğrultusunda $\mathrm{Na}^{+}$konsantrasyonun $\mathrm{CO}_{2}$ tutma verimi üzerine etkisi detaylı olarak incelenmiştir. Deneyler sırasında çözelti içerisindeki katyon miktarı $(1250 \mathrm{ppm}$ $\left.\mathrm{NH}_{4}^{+}, 250 \mathrm{ppm} \mathrm{K}^{+}, 1250 \mathrm{ppm} \mathrm{Ca}^{+2}\right)$ ve diğer parametreler $\left(25^{\circ} \mathrm{C}, 5\right.$ saat, $500 \mathrm{rpm}$ ve $1 \mathrm{~mL}$ trietilenamin $)$ sabit tutulmuştur (Şekil 4). Şekilden de görüleceği üzere ortamdaki sodyum miktarının artışının oluşan çökelti miktarı ile ters orantılı olduğu tespit edilmiştir. Bu düşüşteki en önemli sebeplerden birisi sodyum karbonat bileşiğinin ortamda miktarı fazla olan $\mathrm{CO}_{2}$ tarafından tüketilerek sodyum bikarbonat bileşiğinin oluşmasıdır. 


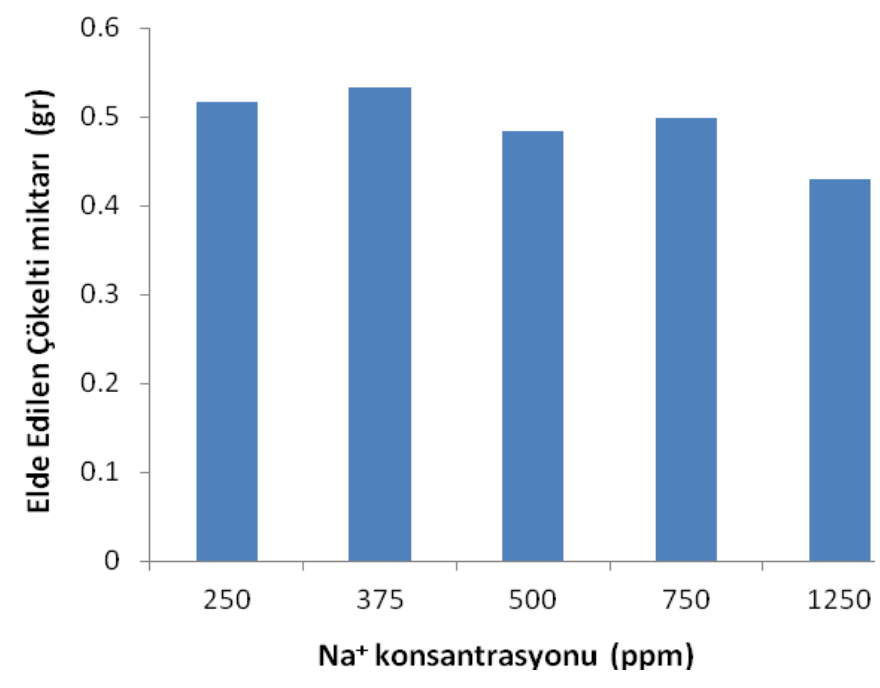

Şekil 4. Sodyum konsantrasyonun çökelti miktarına etkisi.

Tablo 3'de verilen $\mathrm{pH}$ değişimlerinin süre ile olan ilişkisi incelendiğinde ortamda oluşması beklenen $\mathrm{Na}_{2} \mathrm{CO}_{3}$ bileşiğinin artan süre ile yerini $\mathrm{NaHCO}_{3}$ bileşiğine bıraktığı çözeltinin asitleşen $\mathrm{pH}$ değerlerinden ön görülmektedir. $\mathrm{Bu}$ deneysel bulgular literatürdeki çalışmalar tarafindan desteklenmektedir [14].

Tablo 3. Sodyum $\left(\mathrm{Na}^{+}\right)$konsantrasyonlarının $\mathrm{pH}$ üzerine etkisi.

\begin{tabular}{|c|c|c|c|c|c|c|c|c|c|c|c|c|}
\hline $\begin{array}{c}\mathrm{pH} \\
\text { Değişimi }\end{array}$ & Süre (dakika) & 0 & 30 & 60 & 90 & 120 & 150 & 180 & 210 & 240 & 270 & 300 \\
\hline \multirow{2}{*}{} & $250 \mathrm{ppm} \mathrm{Na}^{+}$ & 11,34 & 6,52 & 6,49 & 6,47 & 6,44 & 6,44 & 6,43 & 6,41 & 6,40 & 6,40 & 6,40 \\
\cline { 2 - 13 } & $375 \mathrm{ppm} \mathrm{Na}^{+}$ & 10,56 & 6,73 & 6,66 & 6,35 & 6,26 & 6,25 & 6,23 & 6,21 & 6,18 & 6,18 & 6,16 \\
\cline { 2 - 12 } & $500 \mathrm{ppm} \mathrm{Na}^{+}$ & 9,74 & 6,78 & 6,35 & 6,88 & 6,38 & 6,36 & 6,35 & 6,34 & 6,31 & 6,25 & 6,22 \\
\cline { 2 - 11 } & $750 \mathrm{ppm} \mathrm{Na}^{+}$ & 9,62 & 6,45 & 6,78 & 6,45 & 6,42 & 6,35 & 6,32 & 6,31 & 6,30 & 6,30 & 6,28 \\
\cline { 2 - 10 } & $1250 \mathrm{ppm} \mathrm{Na}^{+}$ & 8,78 & 6,48 & 6,33 & 6,31 & 6,27 & 6,13 & 6,08 & 5,87 & 5,86 & 5,85 & 5,85 \\
\hline
\end{tabular}

Sodyum katyonlarının oluşan çökelti miktarı üzerindeki negatif etkisinden dolayı bir sonraki çalışmalarda 250 ppm'lik $\mathrm{Na}^{+}$konsantrasyonu bundan sonra gerçekleştirilen tüm deneylerde kullanılmıştır.

\subsection{Sürenin $\mathrm{CO}_{2}$ tutma verimi üzerine etkisi}

Reaksiyon süresinin $\mathrm{CO}_{2}$ tutmadaki en önemli parametreler arasında olduğu proje çalışması süresince anlaşılmıştır. Çünkü ortama verilen $\mathrm{CO}_{2}$ gazının bazik özellikli çözelti ile reaksiyonu sonucu çözeltinin pH değişimlerin hızlı olduğu bir ortamda sürenin etkisinin açıklığa kavuşturulması gerekmektedir. Deneyler sırasında çözelti içerisindeki katyon miktarı $\left(1250 \mathrm{ppm} \mathrm{NH}_{4}{ }^{+}, 250 \mathrm{ppm} \mathrm{Na}{ }^{+}, 250 \mathrm{ppm} \mathrm{K}{ }^{+}\right.$, $\left.1250 \mathrm{ppm} \mathrm{Ca}{ }^{+2}\right)$ ve diğer parametreler $\left(25^{\circ} \mathrm{C}, 500 \mathrm{rpm}\right.$ ve $1 \mathrm{~mL}$ trietilenamin) sabit tutulmuştur. 


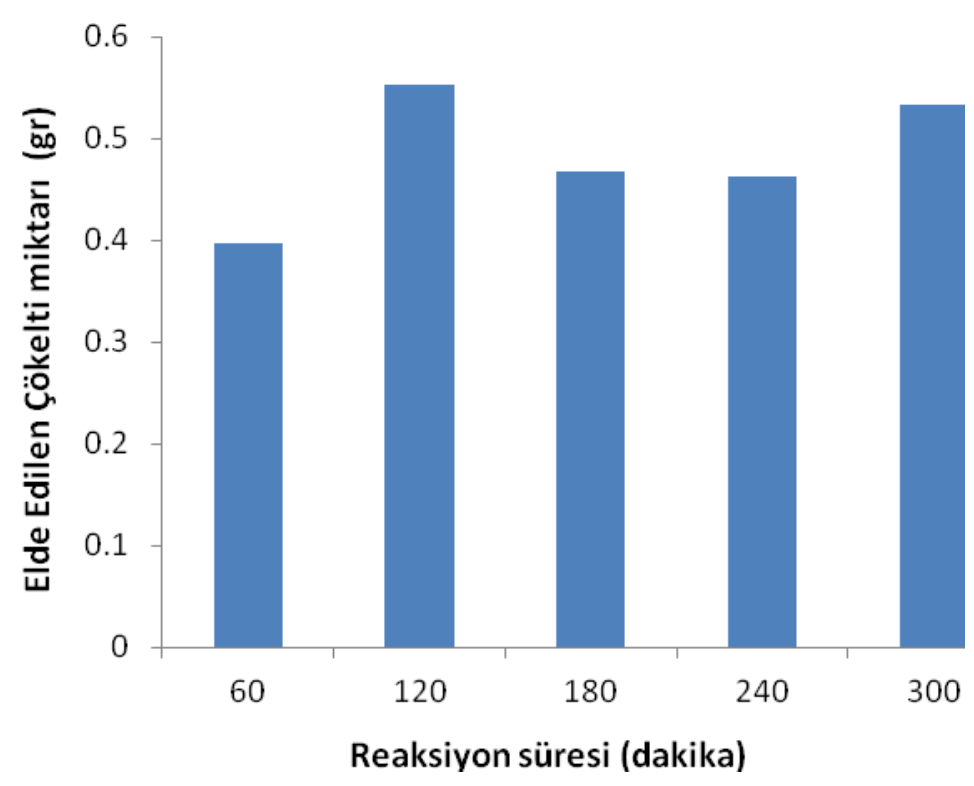

Şekil 5. Reaksiyon süresinin çökelti miktarına etkisi.

Deney sonuçlarının verildiği Şekil 5'den görüleceği üzere reaksiyon süresinin 120 dakika seçildiği deneysel çalışmada en iyi çökelti verimi elde edilmiştir. Sürenin artışı ile birlikte elde edilen çökelti miktarında dalgalanmalar gözlemlenmiş ve genel eğilim olarak doğruluktan bahsedilebilmektedir.

\subsection{Trietilenamin katalizör miktarının $\mathrm{CO}_{2}$ tutma verimi üzerine etkisi}

Adsorpsiyon şartlarına etki eden parametrelerinin incelenmesi sırasında kullanılan trietilenamin $\left(\mathrm{N}\left(\mathrm{C}_{2} \mathrm{H}_{5}\right)_{3}\right)$ katalizörünün miktarının $\mathrm{CO}_{2}$ tutma verimi üzerine etkisi katalizörün miktarının artışı ile olan ilişkisi incelenmiştir. Deneyler sırasında çözelti içerisindeki katyon miktarı (1250 ppm NH${ }_{4}^{+}, 250$ ppm Na $\left.\mathrm{Na}^{+}, 250 \mathrm{ppm} \mathrm{K}^{+}, 1250 \mathrm{ppm} \mathrm{Ca}{ }^{+2}\right)$ ve diğer parametreler $\left(25^{\circ} \mathrm{C}, 2\right.$ saat, $\left.500 \mathrm{rpm}\right)$ sabit tutulmuştur (Şekil 6).

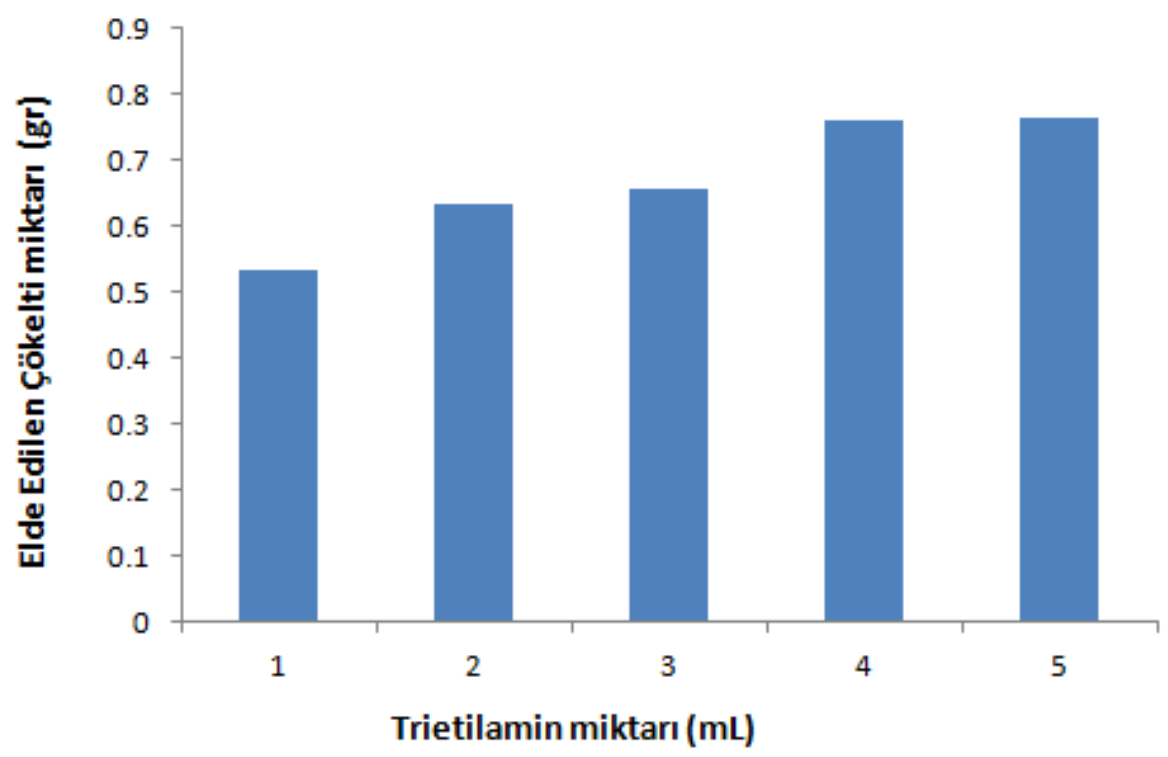

Şekil 6. Trietilamin miktarının çökelti miktarına etkisi.

Şekilden de görüleceği üzere ortamdaki katalizör etkisine sahip organik bileşiğin miktarının artış1 ile birlikte çökelti miktarı ile doğru orantılı arttığ 1 tespit edilmiştir. Bu artıştaki en önemli sebeplerden birisi trietilenamin bileşiğinin ortamdaki $\mathrm{CO}_{2}$ ile reaksiyon şartlarının gelişmesine katkı 
sağlamaktadır. Çünkü organik bileşik içerisindeki amin grubu $\mathrm{CO}_{2}$ ile bağ yaparak çeşitli karbonat çökeleklerinin oluşmasını sağlamaktadır. Ayrıca elde edilen çökelek içerisindeki $\mathrm{CO}_{2}$ miktarının artışı daha farklı bir ifadesiyle çökelek miktarının artışı ile doğru orantılıdır. Grafikten elde edilen veriler doğrultusunda $4 \mathrm{~mL}$ trietilenamin ile en fazla çökelti miktarı elde edilmiştir.

\subsection{Farklı organik katalizörlerin $\mathrm{CO}_{2}$ tutma verimi üzerine etkisi}

Saf sistemler ile yürütülen son deney grubunda daha önceki deneylerden elde edilen veriler doğrultusunda hazırlanan çözeltiler içerisindeki katyon miktarı $\left(1250 \mathrm{ppm} \mathrm{NH}_{4}^{+}, 250 \mathrm{ppm} \mathrm{Na}^{+}, 250 \mathrm{ppm}\right.$ $\left.\mathrm{K}^{+}, 1250 \mathrm{ppm} \mathrm{Ca}{ }^{+2}\right)$ ve diğer parametreler $\left(25^{\circ} \mathrm{C}, 2\right.$ saat, $500 \mathrm{rpm}$ ve $4 \mathrm{~mL}$ farklı organik katalizörler $)$ sabit tutulmuştur (Şekil 7).

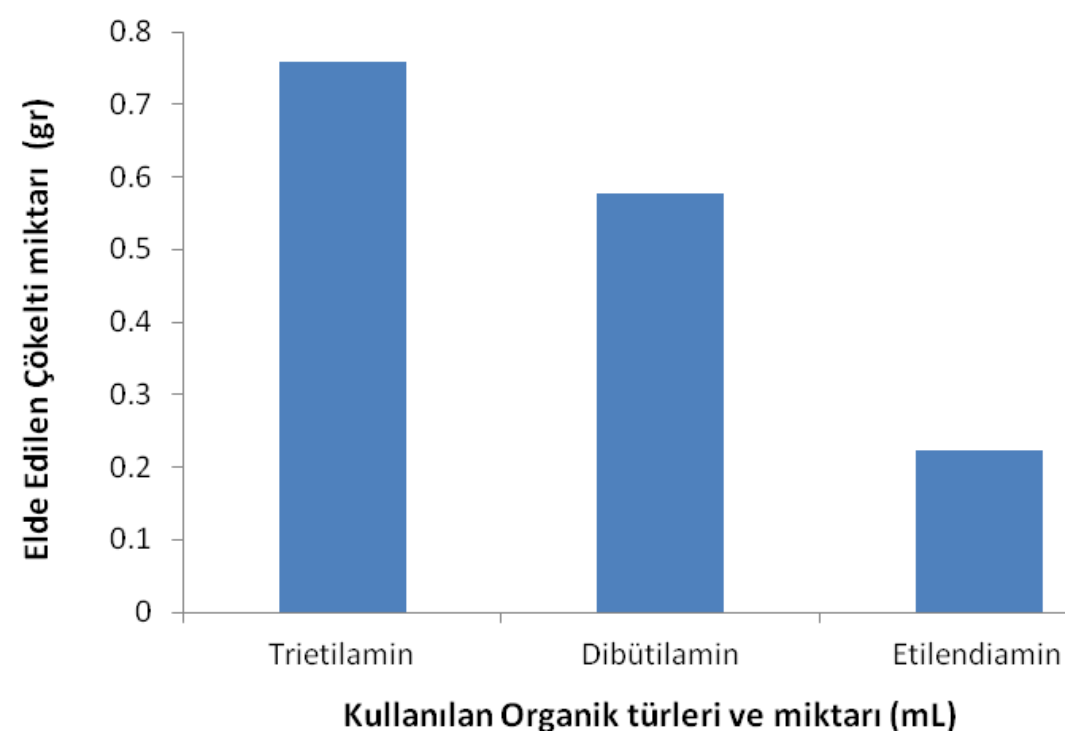

Şekil 7. Farklı organik katalizörlerinin çökelti miktarına etkisi.

Tablo 4'de verilen pH değişimlerinin süre ile olan ilişkisi incelendiğinde deneysel çalışmada farklı amin bileşiklerinin $\mathrm{CO}_{2}$ gazının ortamda var olan katyonlar ile birleşerek çökelti şeklinde sistemde toplanması hedeflenmiştir. Bu deneysel bulgular literatürdeki çalışmalar tarafından desteklenmektedir [12].

Tablo 4. Farklı organik katalizörlerin pH üzerine etkisi.

\begin{tabular}{|c|c|c|c|c|c|c|c|c|c|}
\hline $\begin{array}{c}\text { Süreye göre } \mathrm{pH} \\
\text { değişimleri }\end{array}$ & \multicolumn{7}{|c|}{ Süre (dakika) } \\
\hline Organik türleri & 0 & 15 & 30 & 45 & 60 & 75 & 90 & 105 & 120 \\
\hline $\begin{array}{c}\text { Trietilenamin } \\
\left(\mathrm{N}\left(\mathrm{C}_{2} \mathrm{H}_{5}\right)_{3}\right)\end{array}$ & 11,54 & 10,94 & 8,83 & 6,72 & 6,70 & 6,68 & 6,64 & 6,63 & 6,63 \\
\hline $\begin{array}{c}\text { Dibütilamin } \\
\left.\left(\mathrm{C}_{4} \mathrm{H}_{9}\right)_{2} \mathrm{NH}\right)\end{array}$ & 11,48 & 11,35 & 8,70 & 6,97 & 6,95 & 6,93 & 6,92 & 6,90 & 6,86 \\
\hline $\begin{array}{c}\text { Etilendiamin } \\
\left(\mathrm{C}_{2} \mathrm{H}_{4}\left(\mathrm{NH}_{2}\right)_{2}\right)\end{array}$ & 10,87 & 10,65 & 8,95 & 6,90 & 6,87 & 6,87 & 6,85 & 6,85 & 6,83 \\
\hline
\end{tabular}

Deneysel çalışmadan elde edilen veriler doğrultusunda amin bileşiğinin etrafını çevreleyen etil $\left(-\mathrm{C}_{2} \mathrm{H}_{5}\right)$ ve bütil( $\left(-\mathrm{C}_{4} \mathrm{H}_{9}\right)$ bileşikleri aminin $\mathrm{CO}_{2}$ gazı ile olan reaksiyonunu inhibe ettiği düşünülmektedir. $\mathrm{Bu}$ durum reaksiyon sırasında oluşması beklenen $\mathrm{CO}_{3}{ }^{2-}$ anyonun verimini olumsuz yönde etkilemekte ve çökelti miktarının az olmasına sebep vermektedir. Böylece ortamda var olan katyonların efektif olarak çökmesini engellemektedir. 


\subsection{Elde edilen çökeltilerin karakterizasyonu}

Şekil 8 ve Şekil 9, TG / DTG eğrilerini göstermektedir. Sırasıyla en iyi kalsiyum ve en iyi organik katalizör örneklerine ait sonuçlara göre numunelerde $\% 0,9$ ve $\% 0$ nem bulunmuştur. Ağırlıkça, $\% 45$ 'lik ağırlık kaybına karşılık gelen Şekil 8'de TG eğrilerine göre karbonatın $\left(\mathrm{CO}_{3}\right)$ karbondioksite $\left(\mathrm{CO}_{2}\right)$ ayrıştırılmasını ifade etmektedir. Ayrıca, karbonasyondan sonra elde edilen çökeltinin $\mathrm{Ca}$ esaslı $\mathrm{CaCO}_{3}$ ve/veya $\mathrm{Ca}(\mathrm{OH})_{2}$ olacağ 1 öngörülmektedir. Çünkü bir DTG tepe noktası 700 ile $717^{\circ} \mathrm{C}$ arasındaki sıcaklıklarda tepe noktası gözlemlenmiş̧ir (bir DTG tepe noktası $717,3^{\circ} \mathrm{C}$ ).

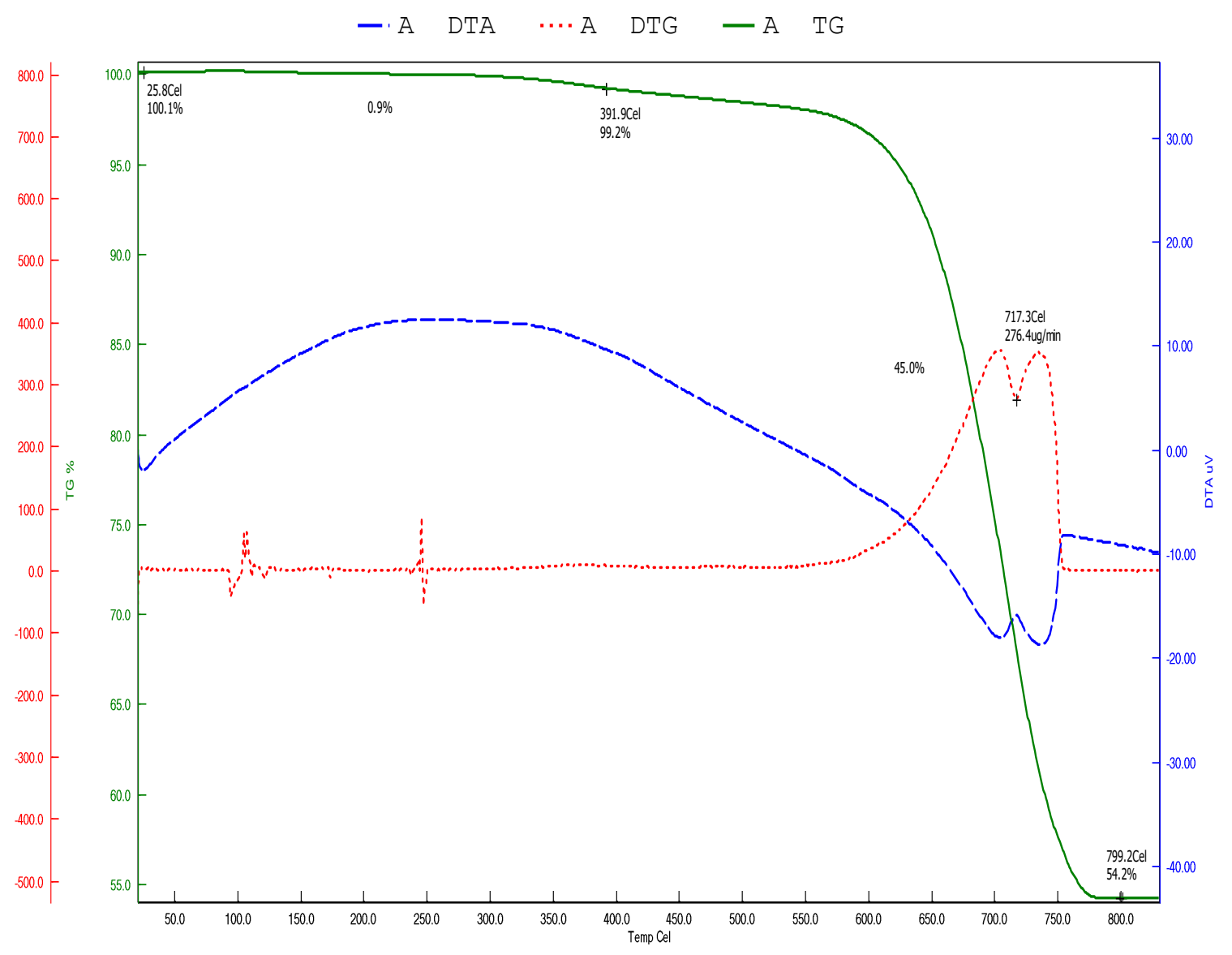

Şekil 8. En iyi $\mathrm{Ca}^{+2}$ verimine sahip çökeltinin Termal analizi.

Şekil 9'dan görüleceği üzere genel olarak, 50 ve $105^{\circ} \mathrm{C}$ arasında numune içerisinde var olan nemi kaybetme ile ilişkili bir kütle kaybı beklenmekte fakat elde edilen grafikte bu şekilde bir kayıp söz konusu değildir. $420^{\circ} \mathrm{C}$ ile $800^{\circ} \mathrm{C}$ arasında yaşanan ağırlık kaybı ise çökelti içerisinde bulunan organik ve elementel karbon, kalsiyum karbonat, kalsiyum hidroksit, magnezyum karbonat ve diğer karbonatlı bileşiklerden ileri gelmektedir.

Elde edilen sonuçlara göre en iyi organik bileşikli verimin elde edildiği numuneden elde edilen çökelti içerisinde yaklaşık $400^{\circ} \mathrm{C}$ ile $800^{\circ} \mathrm{C}$ arasındaki ağırlık kaybı $\% 48,5$ olarak tespit edilmiştir. DTG tepe noktası $689,4^{\circ} \mathrm{C}$ sıcaklığında bir tepe noktası gözlemlenmiştir. 


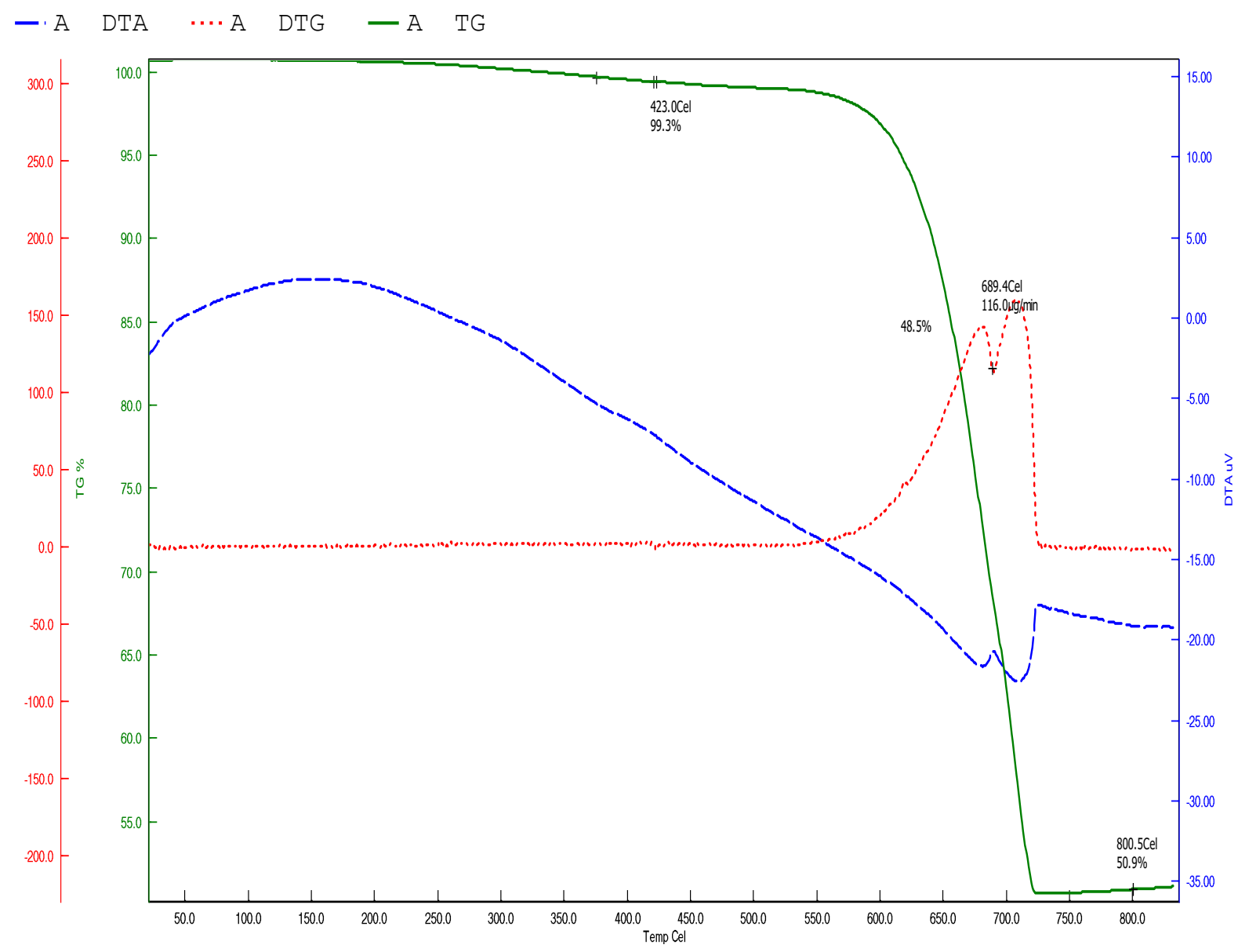

Şekil 9. En iyi organik türününe ait verim değerine sahip çökeltinin Termal analizi.

Elde edilen DTA ve TG sonuçlarına göre; elementel karbon (C), elementel hidrojen $(\mathrm{H})$ ve elementel azot $(\mathrm{N})$ analizleri yapılmış ve sonuçlar Tablo 5'de verilmiştir.

Tablo 5. Farklı organik katalizörlerin $\mathrm{pH}$ üzerine etkisi.

\begin{tabular}{|c|c|c|c|}
\hline Örnek Şartları & $\begin{array}{c}\% \mathrm{C} \\
(\text { Ağırlıça })\end{array}$ & $\begin{array}{c}\% \mathrm{H} \\
(\text { Ağırlıça })\end{array}$ & $\begin{array}{c}\% \mathrm{~N} \\
(\text { Ağırlıça })\end{array}$ \\
\hline En iyi $\mathrm{Ca}^{+2}$ iyon verimi & 12,3 & 0,9 & 1,1 \\
\hline En iyi Na+ iyon verimi & 12,5 & 1,1 & 1,0 \\
\hline En reaksiyon süre verimi & 12,3 & 1,1 & 1,3 \\
\hline En iyi trietilenamin verimi & 12,5 & 1,1 & 1,5 \\
\hline
\end{tabular}

Tablodan da görüleceği üzere \%C değerleri ortalama olarak \%12,4 olarak tespit edilmiştir. Oluşan çökeltinin genel olarak $\mathrm{CaCO}_{3}$ esaslı olduğu düşünülürse; bu yapı içerisindeki $\% \mathrm{C}$ içeriği $\% 12$ olması beklenmektedir ki, bu değer bizim deneysel olarak elde ettiğimiz bulgular ile örtüşmektedir. Ayrıca, sisteme eklenen amin esaslı organik bileşik bir miktar çökeltinin yapısında yer aldığı ölçülen $\% \mathrm{~N}$ değerleri ile anlaşılmaktadır. 


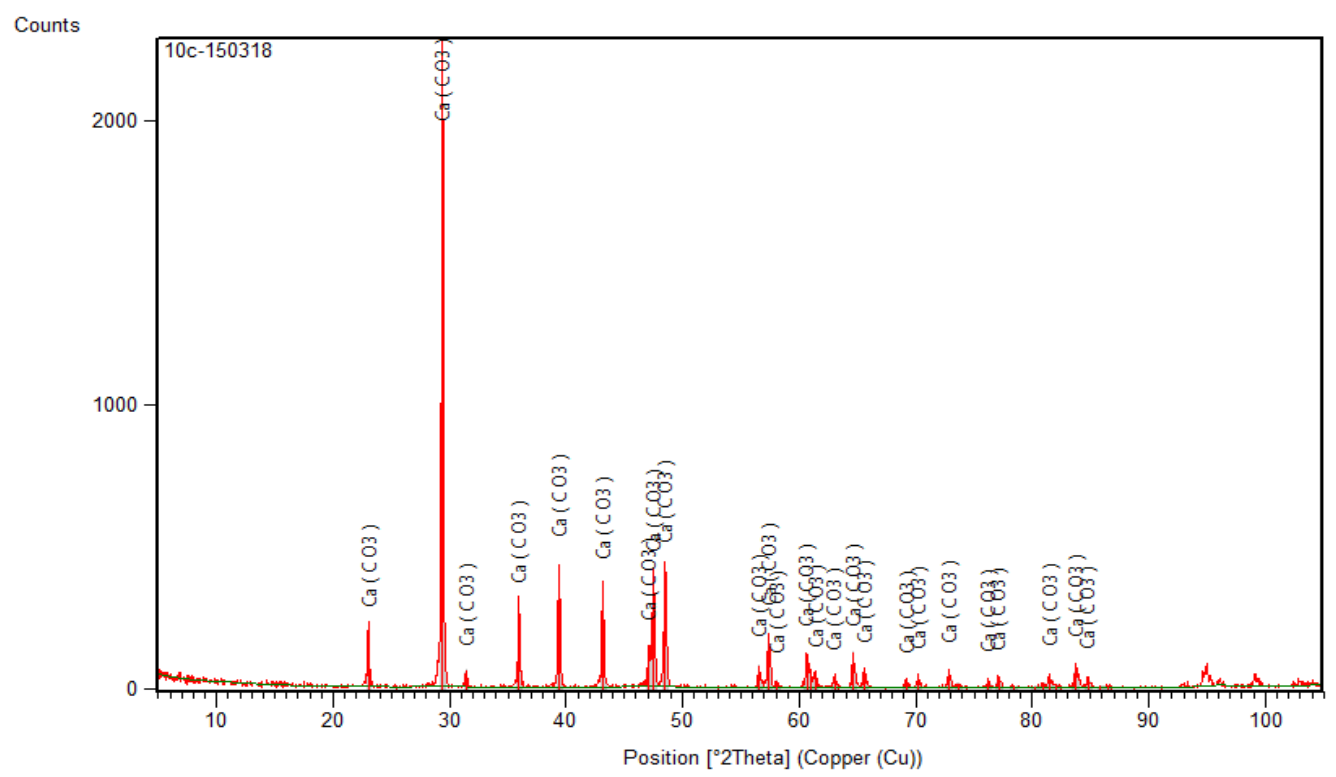

Şekil 10. En iyi verim ürününe ait X-ışınları kırınımı analizi.

Şekil 10 'da en iyi verim ürünlerine ait analiz sonuçlarında yapının $\mathrm{CaCO}_{3}$ esaslı olduğu anlaşılmıştır. Elde edilen değerler Tablo 5'de verilen değerler ile örtüşmektedir.

\section{Sonuç ve Öneriler}

$\mathrm{Bu}$ araştırma makalesinde $\mathrm{CO}_{2(\mathrm{~g})}$ gazının (sera gazı) endüstriyel atıklar içerisinde kolaylıkla bulunabilecek oksitlerden $\left(\mathrm{CaO}, \mathrm{K}_{2} \mathrm{O}\right.$ ve $\left.\mathrm{Na}_{2} \mathrm{O}\right)$ yararlanılmıştır. Bu oksitler esas alınarak hazırlanan saf sistem ile karbondioksit gazı kimyasal adsorpsiyon yoluyla tutulmuştur. Deneyler sonucu elde edilen veriler doğrultusunda endüstriyel katı atıkların zararlarını asgariye indirmek ve atmosferde çok fazla miktarda bulunan karbondioksitin tutulabilmesine imkân sağlayacak bir ön çalışma gerçekleştirilmiştir. $\mathrm{Bu}$ sayede endüstriyel katı atıklar için yeni bir bakış açısı ortaya konulması çalışılmıştır. Halihazırda oldukça bol ve nispeten ucuz olan bu atık maddelerden ekonomik bir adsorban üretilebileceğine elde edilen en iyi deneysel bulgular şu şekildedir: $1250 \mathrm{ppm} \mathrm{NH}_{4}^{+}, 250 \mathrm{ppm} \mathrm{Na}^{+}, 250 \mathrm{ppm} \mathrm{K}{ }^{+}, 1250 \mathrm{ppm}$ $\mathrm{Ca}^{+2}$ katyonu içeren $200 \mathrm{~mL}$ 'lik çözelti $25^{\circ} \mathrm{C}, 500 \mathrm{rpm}$ ve $4 \mathrm{~mL}$ trietilenamin katalizörlügünde reaksiyon sonucu \%100 verimle $\mathrm{CaCO}_{3}$ çökeleği elde edilmiştir.

\section{Teşekkür}

Bu çalışma; Kahramanmaraş Sütçü İmam üniversitesi bilimsel araştırma projeleri koordinasyon birimi tarafindan 2017/5-14 M numaralı proje kapsamında desteklenmiştir. Makalenin bilimsel olarak gelişimine katkı sağlayan hakemlere ve derginin bölüm editörüne teşekkür ederiz.

\section{Kaynaklar}

[1] Başaran M. 2007. Karbondioksit (CO2) tutma ve depolama, TMMOB Türkiye VI. Enerji Sempozyumu - Küresel Enerji Politikaları ve Türkiye Gerçeği, pp 442-456, 22-24 Ekim, Ankara.

[2] Aresta M., Dibenedetto A., Quaranta E. 2015. Reaction Mechanisms in Carbon Dioxide Conversion, Berlin: Springer.

[3] Lackner K.S., Wendt C.H., Butt D.P., Joyce E.L., Sharp D.H. 1995. Carbon dioxide disposal in carbonate minerals, Energy, 20 (11): 1153-1170.

[4] Seinfeld J.H., Pandis S.N. 2016. Atmospheric chemistry and physics: from air pollution to climate change, John Wiley \& Sons publishing, 908s. London.

[5] Seifritz W. 1990. $\mathrm{CO}_{2}$ disposal by means of silicates, Nature, 345 (6275): 486-491.

[6] D'Alessandro D.M., Smit B., Long J.R. 2010. Carbon dioxide capture: prospects for new materials, Angewandte Chemie International Edition, 49 (35): 6058-6082. 
[7] Goeppert A., Czaun M., Prakash G.S., Olah G.A. 2012. Air as the renewable carbon source of the future: an overview of $\mathrm{CO}_{2}$ capture from the atmosphere, Energy \& Environmental Science, 5 (7): 7833-7853.

[8] Kumar A., Madden D.G., Lusi M., Chen K.J., Daniels E.A., Curtin T., Perry J.J., Zaworotko M.J. 2015. Direct air capture of $\mathrm{CO}_{2}$ by physisorbent materials, Angewandte Chemie International Edition, 54 (48): 14372-14377.

[9] Park S., Song K., Jeon C.W. 2016. A study of mineral recovery from waste ashes at an incineration facility using the mineral carbonation method, International Journal of Mineral Processing, 155: (2016) 1-5.

[10] Dirar Q.H., Loughlin K.F. 2013. Intrinsic adsorption properties of $\mathrm{CO}_{2}$ on 5A and 13X zeolite, Adsorption, 19 (6): 1149-1163.

[11] Orhan O.Y., Alper E. 2015. Kinetics of Carbon Dioxide Binding by Promoted Organic Liquids, Chemical Engineering \& Technology, 38 (8): 1485-1489.

[12] Orhan O.Y., Tankal H., Kayi H., Alper E. 2016. Kinetics of $\mathrm{CO}_{2}$ capture by carbon dioxide binding organic liquids: Experimental and molecular modelling studies, International Journal of Greenhouse Gas Control, 49 : 379-386.

[13] Orhan O.Y., Ume C.S., Alper E. 2017. The Absorption Kinetics of $\mathrm{CO}_{2}$ into Ionic Liquid-CO Binding Organic Liquid and Hybrid Solvents. Energy Efficient Solvents for $\mathrm{CO}_{2}$ Capture by GasLiquid Absorption, Editted by W.M. Budzianowski, Springer Press, 241-261.

[14] Zeman F.S., Lackner K.S. 2004. Capturing carbon dioxide directly from the atmosphere, World Resource Review, 16 (2): 157-172.

[15] Ünveren E.E., Monkul B.Ö., Sarığlan Ş., Karademir N., Alper E. 2016. Solid amine sorbents for $\mathrm{CO}_{2}$ capture by chemical adsorption: A review, Petroleum, 3 (1): 37-50.

[16] Wang T., Lackner K.S., Wright A. 2011. Moisture swing sorbent for carbon dioxide capture from ambient air, Environmental science \& technology, 45 (15): 6670-6675.

[17] Wang T., Liu J., Fang M., Luo Z. 2013. A moisture swing sorbent for direct air capture of carbon dioxide: Thermodynamic and kinetic analysis, Energy Procedia, 37 (2013): 6096-6104.

[18] Keith D.W. 2009. Why capture $\mathrm{CO}_{2}$ from the atmosphere?, Science, 325 (5948): 1654-1655. 